\title{
The Analysis of E-Government Services Adoption and Use in Slovenian Information Society between 2014 and 2017
}

\author{
Mitja Dečman \\ University of Ljubljana, Faculty of Administration, Slovenia \\ mitja.decman@fu.uni-lj.si
}

\section{ABSTRACT}

With the increasing role of information and communication technology (ICT) in the society, ICT's role is gaining importance in the aspect of provision and use of the public-sector services for the citizens. Especially in the European Union different activities have been conducted through the years to promote ICT use in the society. It has been mainly based on the Digital Agenda for Europe (DAE), which underlines the key role of ICT in the efforts to achieve its strategic objectives. Slovenia as an EU member state follows these directions but positions itself among less successful states in the EU. The well-known European Digital Economy and Society Index ranks Slovenia to the lower half of member states indicating possibilities for improvement. Although much can be said and done about the service-providers side this paper focuses on the users' side and especially on their digital inequality. The lack of studies in the area of digital inequality and online government services adoption and use is the main motivation for this research. The research uses the data provided by Slovenian annual survey Use of Information and Communication Technology in Households and by Individuals of the last four years. The analysis of this data, presented in the paper, exhibits that changes for the better are detected in Slovenian society, but the situation in public-sector services is not optima. The results demonstrate the existence of digital inequality considering the income level of households and education level of individual users. The synthesis of the data demonstrates that the Slovenian government and its ministries should consider adding tangible actions to the already set strategies if the country wants to catch up with the leading countries of the EU and achieve goals, set by the DAE.

Keywords: digital inequality, digital divide, e-government, e-services use, information society, Slovenia 


\section{Introduction}

Globally, as well as in Slovenia, the importance of information and communication technology (ICT) in society is increasing; furthermore, the technology performance, the scope of use, and the number of jobs that require its application, and consequently the relevant digital skills and knowledge, are also growing. Hüsing et al. (2015) estimate that by 2020 the European Union will have 750,000 jobs related to the information and communication technology available. Furthermore, studies of the United States, Japan, and nine European countries carried out between 1980 and 2004 revealed that fast-growing tech economies shift the education requirement from medium-skilled workers towards highly educated workers with appropriate ICT polarisation (Michaels, Natraj, and Van Reenen, 2014).

Digital skills and knowledge are important parameters of digital services adoption and use, being in private or public sector. In public sector technology has long been present with a goal to increase the efficiency and effectiveness of internal operations between public sector organisations (G2G) and the private sector (G2B) and citizens (G2C) (Weerakkody, El-Haddadeh, Sabol, Ghoneim, and Dzupka, 2012). With the use of ICT and thus faster and more efficient services, countries can make important savings. For example, following the successful introduction and use of e-procurement, the European Commission assessed annual savings of EUR 100 billion on the EU level (Davies, 2015). Merely with the opening of public sector data and offering this data to the public and the private sector via the Internet, the European Union estimates the creation of a market with an annual turnover of EUR 32 billion (Gascó-Hernández, 2014, p. 172). The government in Dubai, the first to exploit "blockchain technology", foresees that this technology will make savings of USD 3 billion in document management (Hughes, Graham, Rowley, and Lowe, 2018). On the other hand, $I C T$, in which the Internet certainly takes the lead, can also be successfully used by citizens. With technology-supported means, they can gain more relevant information faster and more effectively, improve and speed up communication with public sector institutions or their employees and perform various procedures at the level of transactional services without changing their physical location or being limited by official hours. Research shows that this saves time (Carter, Schaupp, Hobbs, and Campbell, 2012), costs (Wang and Liao, 2008), and raises the quality of administrative services (Sharma, 2015).

The key challenge is that the offer has to meet demand and use. Digital services require digitally equipped citizens, both in terms of technology and knowledge. Digital inequality, which sets out differences in society with regard to the use of ICT, has been present since the very beginning of information society. Tilly (1998) defines it in terms of inequality in the distribution of information resources in society, as a result of competitions between pairs of social categories, such as men - women, educated - uneducated, elderly - young, rich - poor, etc. Inequalities, which are often based on gender, education, income, 
place of residence, and other parameters, indicate that for the full use of ICT in information society the first step must be the full familiarisation with the situation and users, followed by strategies, action plans, and concrete projects to finally reduce digital inequality and establish successful information society for all. Such society is the basis for the good use of e-government.

To our knowledge there exists a lack of studies in the area of digital inequality and online government services adoption and use. This was therefore the main motivation for our research. The article focuses on the state of information society in Slovenia, more specifically, on the scope of public administration e-service, even though all members of the European Union face similar challenges (Chipeva, Cruz-Jesus, Oliveira, and Irani, 2018; Cruz-Jesus, Vicente, Bacao, and Oliveira, 2016). Through the data analysis of the survey questionnaire Use of Information and Communication Technology in Households and by Individuals, which has been carried out by the Statistical Office of the Republic of Slovenia since 2008, we have determined and defined two research hypotheses.

In the second section, we define information society and digital inequality, the state of information society in Slovenia, which we then link with the development of Slovenian e-government. Through an overview of strategies we analyse the situation in today's society and identify the challenges that the Slovenian public sector and its e-government are facing. In the third section, we present a comparison of the situation over four years and the progress in individual areas or indicators of information society through a detailed analysis of the data between 2014 and 2017. Through the prism of influential factors of an individual's education and household income, we identify critical parameters for unsuitable conditions in the field of information society and e-government. In the last section, we provide a set of proposals through the synthesis and discussion and conclude with the guidelines for better development of this area in the future. This article contributes to the literature on digital divide by detecting and exploring the importance of main digital inequality factors in Slovenian society. At the same time the results can help Slovenian government to detect and improve the conditions in the society and react by conducting adequate activities in the future. Similar factors might be detected in other EU countries using the same statistical resources and similar or different actions might be conducted in those countries as well. The methodology and the results might be also used to extend the researched period to previous or future years to improve the longitudinal analysis in different EU states.

\section{Theoretical Background}

\subsection{Information society and e-government}

Information society began to develop in the nineties when information technology and the emerging Internet penetrated the wider social environment and simultaneously coincided with some other social, economic, and cultural 
transformations (Castells, 2011). Misuraca et al. (2013) state that information society, the focus of which is on socioeconomic effects, emerged from the use of IT in the private sector, which expanded into general society. Nath (2017), similar to Webster (2014, p. 10), distinguishes five characteristics of information society: technological, economic, sociological, spatial, and cultural, the essential element being the technology that is or is not available to the individual in it its own private or business environment. Regardless of the above mentioned characteristics, differences between individuals or households are defined as digital inequality or digital divide. The OECD (2001) defines the digital divide as the difference between individuals, households, organisations, or geographical units with different socio-economic levels in terms of access to ICT and the use of the Internet for a wide range of activities. In the first surveys in this field, this gap was defined primarily from the perspective of unequal access opportunities to technology (DiMaggio, Hargittai, Celeste, and Shafer, 2004). Later, the digital divide was upgraded into digital inequality, adding two more aspects - inadequate knowledge and skills, and psychological and cultural constraints and differences (J. van Dijk and Hacker, 2003).

Thus, information society, with the help of ICT, improves the social situation of each individual and intervenes in business, private, and public-administrative spheres. A special branch of administrative science has developed through the increasing role of technology in the public sector, i.e. e-government. According to some definitions, the concept of e-government means the intensive use of the Internet for dealings with the administration - between administrative bodies within the administration, externally with citizens, companies, and other organisations. Most of the e-government definitions emphasise the importance of technology and the ability to transform and improve public administration processes. E-government is a common product of information technology and new principles of public administration, which have been a key element of the renewal of public services implemented by many countries in the 21st century (Yuan, Xi and Xiaoyi, 2012). The main concept of e-government is focused on empowering public institutions with electronic means and the introduction of e-governance as a vision of changing the nature of the state and its functioning (Garson, 2006, p. 19). Recent surveys in this area distinguish between the term e-government and e-governance. E-governance defines the framework for organising, planning, coordinating, managing, and monitoring strategies and activities with the support of ICT and especially the Internet (Palvia and Sharma, 2007). In this respect, UNESCO further highlights the involvement of citizens and wider society in decision-making processes with the aim of increasing the efficiency, transparency, and accountability of the state.

One of the key focuses of e-government services are the citizens. In the socalled Government to Citizen (G2C) area of e-government the public administration offers most different information and online services using various electronic channels. In this regard the European Commission adopted the Eu- 
rope 2020 strategy (European Commission, 2010b), which aims to bring the EU economy out of crisis and prepare for the challenges of the next decade. One of the main objectives of the strategy is to promote the Internet and its use by all EU citizens, especially activities to increase digital literacy and accessibility. The strategy includes seven flagship initiatives, including the Digital Agenda for Europe (DAE), which underlines the key role of ICT in the efforts to achieve its strategic objectives (European Commission, 2010a). The chapter on digital literacy thus indicates that in 2010 as many as 30\% of the EU population had never used the Internet (which is 150 million people), most often because they feel that they do not need it or because it is too expensive which is unacceptable from the view of information society progress. This group is mostly composed of population aged 65 to 74, those with low incomes, the unemployed, and less educated. In such a way digital illiteracy also influences the low level of e-government use and diminishes investments in it.

\subsection{E-government and information society of Slovenia}

Within the frames of the Digital Agenda for Europe, Slovenia has adopted the Digital Slovenia 2020 - Development strategy for the information society until 2020 (Ministry of Education, Science and Sport, 2016a) and associated strategic documents for the Next Generation Broadband Network Development Plan to 2020 (Ministry of Education, Science and Sport, 2016b) and the Cyber Security Strategy (Government of the Republic of Slovenia, 2016). In its analytical part, the Digital Slovenia 2020 strategy identifies unsuitable conditions of Slovenian society in this field and the lagging behind many EU countries indicating, inter alia, as reason the low level of investment in the development of information society and insufficient general awareness of the importance of ICT and the Internet for the development of the economy, state, and the entire society. Digital Slovenia 2020 foresees the following measures to eliminate the major digital gaps in the field of digital society: faster development of digital entrepreneurship, greater competitiveness of the ICT industry, general digitisation, the development of digital infrastructure, the construction of broadband infrastructure, the improvement of cyber security, and the development of an inclusive information society. These actions also coincide with the OECD Bridging the digital divide report (OECD, 2018). In terms of improving information society, the objectives of the strategy are:

- Raising general awareness of the importance of ICT and the Internet for the development of society;

- Sustainable, systematic, and focused investment in the development of a digital society;

- General digitisation according to the digital by default principle;

- Intensive and innovative use of ICT and the Internet in all segments of society;

- High-speed access to open Internet for all; 
- An inclusive digital society,

- Safe cyberspace;

- Confidence in cyberspace and protection of human rights (MIZŠ, 2016).

In view of the development of e-government, Slovenia has established and implemented a number of strategies and action plans. The latest strategy, the Public Administration Development Strategy from 2015 to 2020 (Ministry of Public Administration, 2015), includes a special chapter entitled Effective informatics, increased use of e-services and interoperability of information solutions. These steps are necessary, as Slovenia is lagging behind in the use of public administration websites ( $18^{\text {th }}$ place), in obtaining forms ( $14^{\text {th }}$ place), and electronic submission of forms to public sector institutions ( $17^{\text {th }}$ place) according to the European Digital Economy and Society Index (DESI) (European Commission, 2018). The strategy defines the following objectives:

- Unification and modernisation of entry points for citizens and the economy, portal integration;

- Establishment of a single contact centre of the government administration;

- Increased offer of more comprehensive life events coverage (expansion of the one-stop-shop concept, a single point of access, digitalisation of the entire process from start to finish, compliance with actual user needs, and active involvement of end users in all phases of development and implementation);

- Simplified use of electronic services and digital channels for end-users;

- Improvement of technical mechanisms for publishing useful and up-to-date open public sector data;

- Promotion of the improvement of the coverage of broadband communication channels;

- Inform users of electronic services and the advantages of digital communication, cooperation in promoting information society development, continuous education and promotion.

Based on decades of Slovenia's activities in the development of the information society and e-government, the adopted strategies that Slovenia has been carrying out for several years and the successful economic growth of the country in the recent past, we can set up the following hypotheses:

- In the period under review, Slovenia has advanced in terms of the level of use of public sector e-services;

- The differences in terms of digital inequality are decreasing, in particular with regard to education and socio-economic status. 


\section{Methods}

\subsection{Participants}

The target group is the population of the Republic of Slovenia aged between 16 and 74 and their households. Respondents are selected randomly, whereby adequate representativeness of all demographic parameters, such as age, education, income class, and others is ensured in the sampling. Data on citizens and households is weighted accordingly, thus representing the representativeness of results over the entire Slovenian population. In order to ensure comparison of survey results during the years, representative samples are provided by Statistical Office of the Republic of Slovenia (SORS), and although respondents are not the same each year, the sample representation guarantees a sufficiently high level of reliability of results for longitudinal research (SORS, 2018).

\subsection{Instrument}

Data was collected in cooperation with the SORS and is based on the annual survey Use of Information and Communication Technology in Households and by Individuals (SORS, 2018). The data was obtained for 2014, 2015, 2016, and 2017. Since the questionnaires have structurally and substantively changed over the years, we had to determine the variables (questions) that remained the same over the years, which consequently reduced the set of indicators suitable for longitudinal analysis. At the same time, due to the minimum possible scope of the questionnaire used by SORS at the annual level, certain questions are exchanged every two years, often also due to the demands of European or other international institutions (e.g. Eurostat, the United Nations International Telecommunication Agency, etc.) causing another decrease of possible variables. Although the number of questions and consequently variables has increased over the years (from 139 in 2014 to 199 in 2017), we have ultimately determined 73 questions that remain the same over the years.

The questionnaire is primarily aimed at addressing regular Internet users, i.e. those who have used the Internet in the last 3 months; however, certain questions aim to address those who have used the Internet in the last 12 months. Some questions are aimed at addressing all respondents, regardless of whether they use the Internet or not. These are, in particular, questions about the state of the household information technology equipment or Internet access, regardless of which household member uses it. In addition to the set of questions about the state in the household, through the years the use of the Internet by the respondent is addressed by a series of questions about:

Means of accessing the Internet (technologies);

- Internet activities;

- Use of the Internet in connection with the public sector; 
- Use of the Internet for shopping;

- Digital skills of the respondent.

\subsection{Procedure}

Before the analysis, we prepared a database containing data on 1611 respondents in 2014, 1648 respondents in 2015, 1568 respondents in 2016, and 1670 respondents in 2017. We used Microsoft Excel and SPSS 25 software to analyse the data. The chi-square test for homogeneity was used for advanced analysis of the dependence of the level of education and the income group on individual measurable values. The conditions of this test are met, as we operate with dichotomous dependent variables, categorical independent variables with more than three values; the independence of observation and a sufficiently large sample $(N>1600)$ are ensured, and so is the condition of minimum frequency 5 per processing cell. Upon detailed analysis of the use of public administration services over the years and exploration of the impact of education and monthly income, we can determine the statistically significant effects of both independent variables. At the same time, Z-test for comparison of proportions (post-hoc test) with a significance level of at least $p<.05$ and Bonferon correction can help us determine groups or categories among which there are statistically significant differences (Agresti, 2007).

\section{Results and Analysis}

The first prerequisite for an empowered citizen in an information society, i.e. a digital citizen is the access to computer hardware (computer, smartphone, tablet, etc.) and the Internet (J. van Dijk and Hacker, 2003). The latter does not depend solely on an individual, but rather on the situation in the household, as not everyone needs his own device and access (a shared computer or a tablet in the household), although with today's ubiquitous smartphones and inexpensive data packets it is becoming more common that each individual owns a device. The results show (Figure 1) that in 2017 almost $82 \%$ of Slovenian households had access to the Internet, whereby there was also a significant increase in mobile access (in 2017, 69.5\% of households), while the share of households with broadband (xDSL) or cable access remains between 25 and $30 \%$. The detailed results examination shows an alarming difference in terms of income disparities, as there is 51 percent share of households with Internet access within the lowest tax class (household monthly net income up to EUR 700), and 100 percent share within the highest tax class (household monthly net income exceeding EUR 2100). 
Figure 1: Share of households with access to the Internet

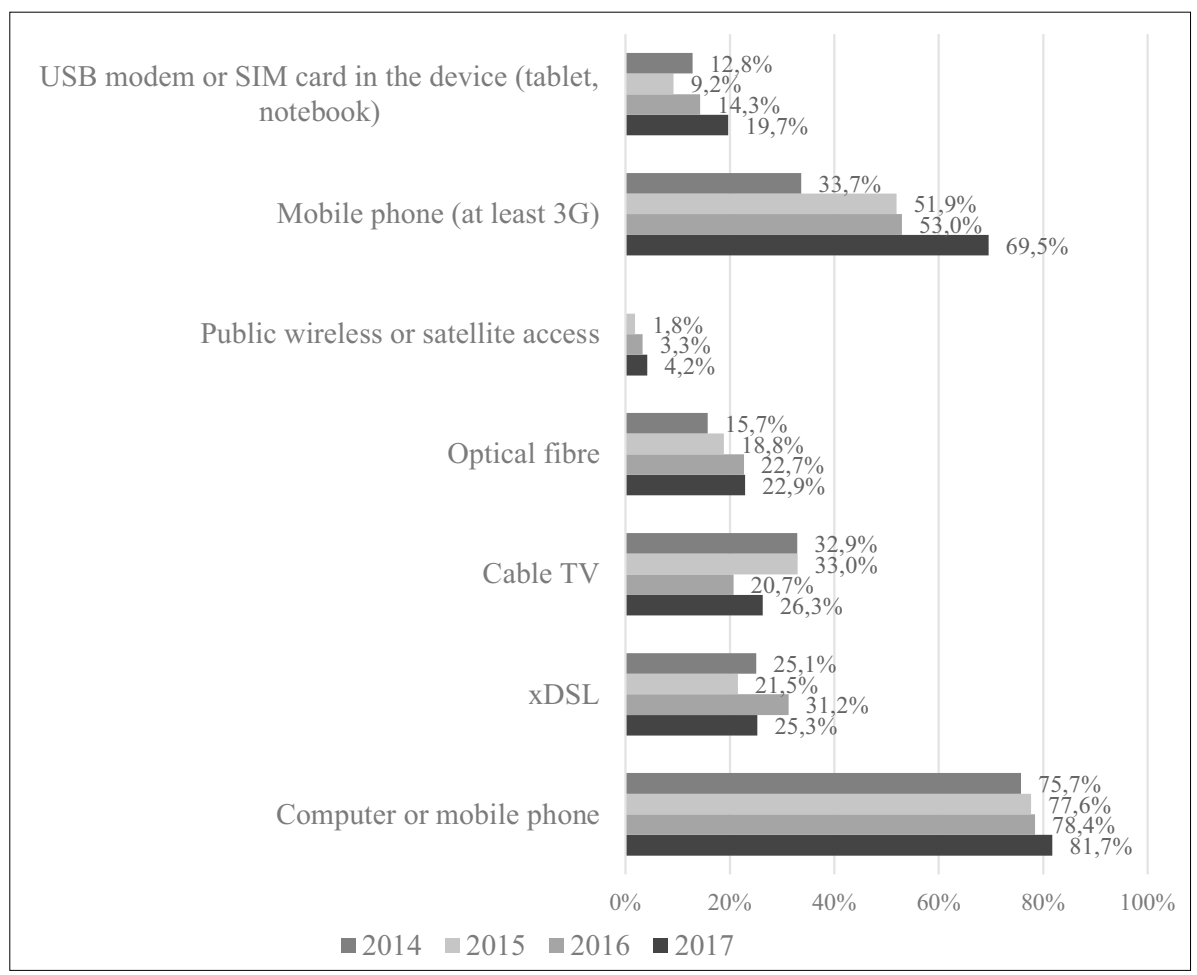

Source: own.

Over the years, the lack of need remains one of the main reasons why households do not have access to the Internet (Figure 2); however, the impact of equipment and access costs, inadequate knowledge and the inaccessibility of broadband have decreased as the reason for Internet inaccessibility. 
Figure 2: Share of households that do not have access to the Internet for various reasons

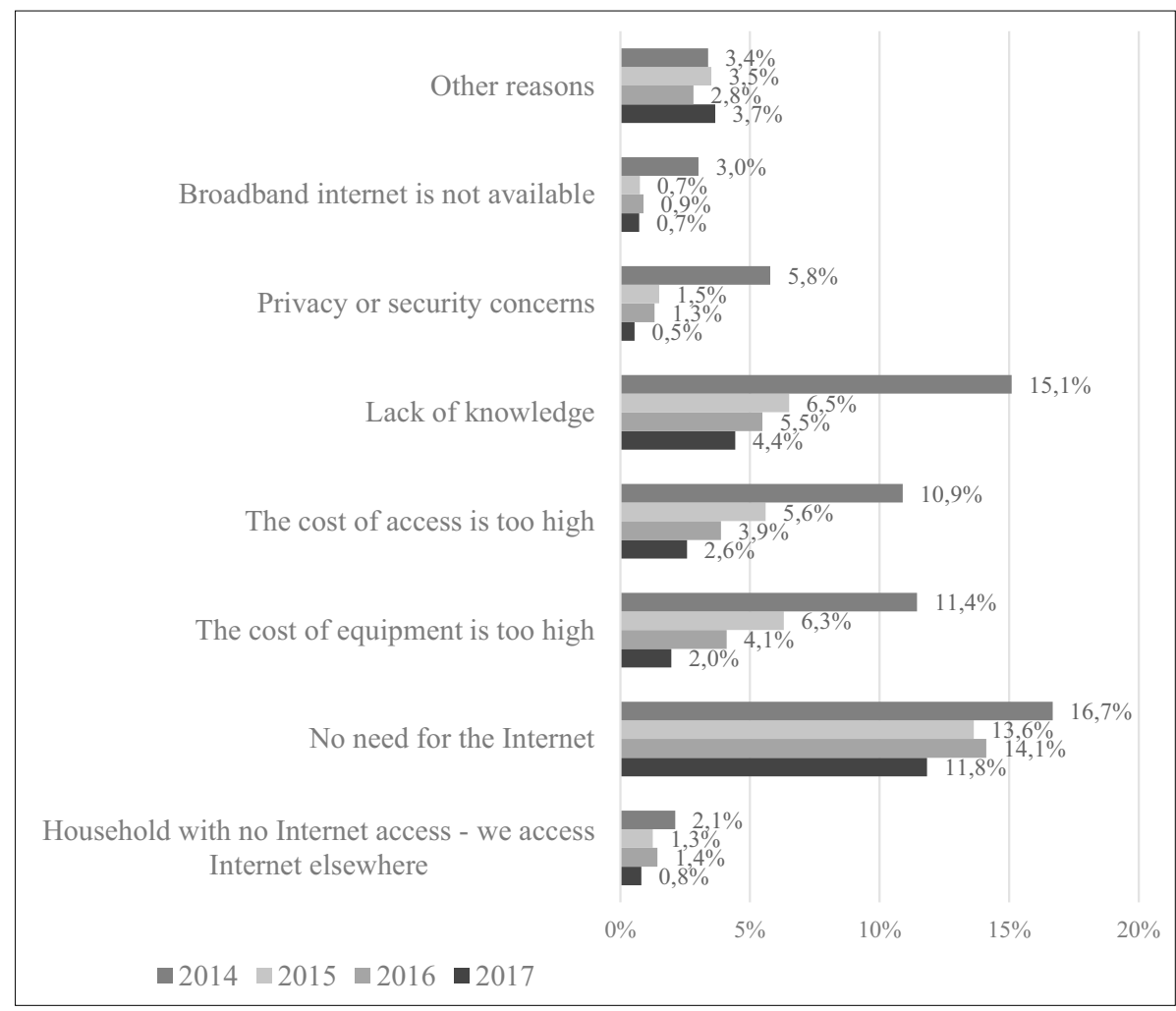

Source: own.

Once a user has access to technology and the Internet, he can start to take advantage of all the benefits in this respect; however, he is required to have at least some basic knowledge. The higher the level of knowledge, the more demanding technology and solutions, and the larger range thereof, may the user apply and exploit. The questionnaire itself does not include questions about basic knowledge, such as the use of browser or search engine, but focuses on more demanding processes, such as creating and calculating spreadsheets, managing files, creating and moving multimedia documents and programming. As shown in the figure below (Figure 3, data includes only those respondents who used the Internet in the last 12 months), the least users know how to write computer programs - although in recent years the EU has invested a lot in education and training providing this type of knowledge. In almost all indicators of knowledge, the share does not change drastically through the year and shows some type of stagnation of Slovenian society in this field. 
Figure 3: Share of individuals with certain computer knowledge and skills

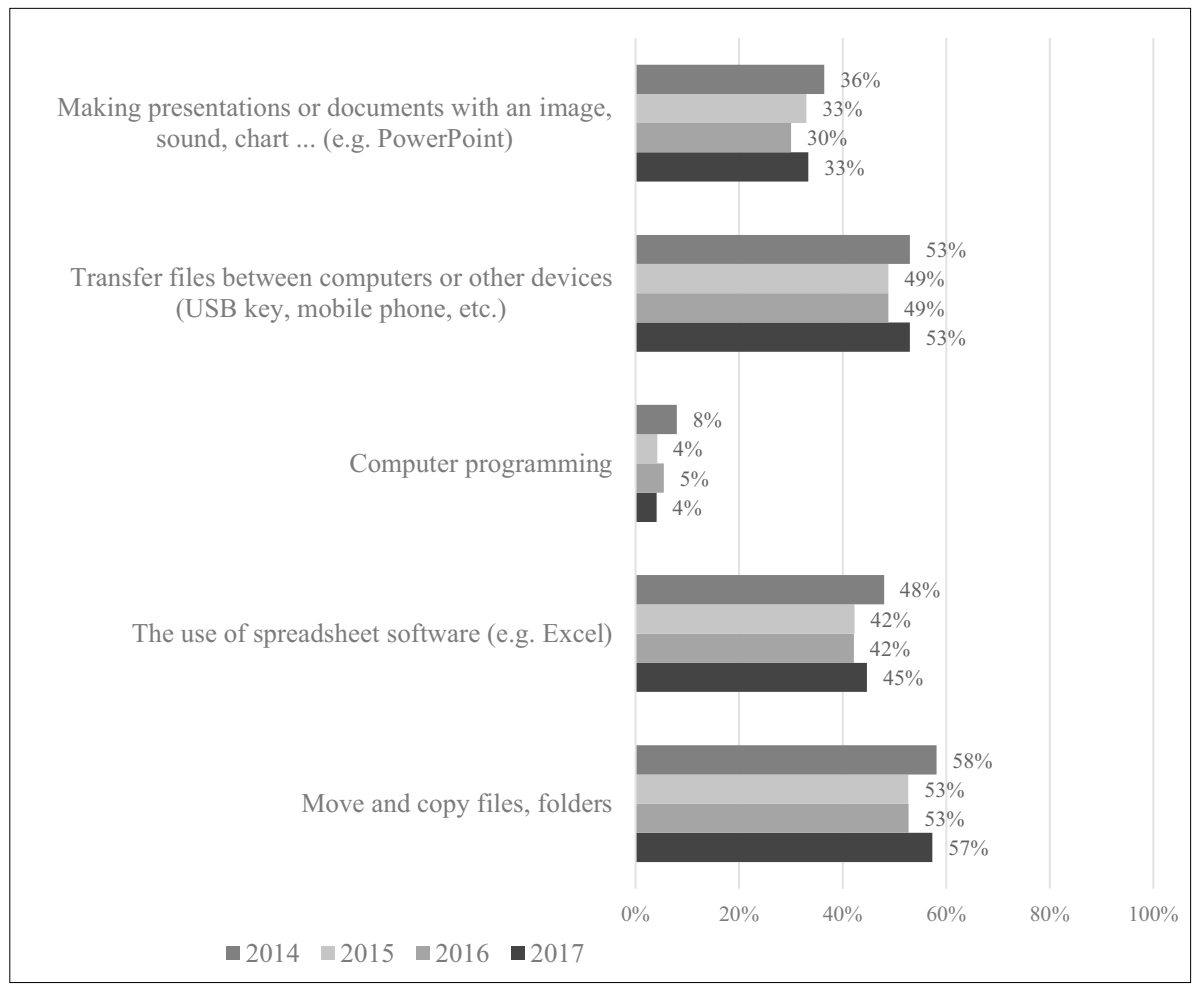

Source: own.

Based on relevant knowledge, the user can start to exploit everything that the Internet offers. Some of the most commonly used services are e-mail, reading of online news, magazines, and newspapers, and search of information on products and services (Figure 4). Slovenian citizens least use video telephony, online sales, and sharing of own photos, videos, music, and text online. Although the latter can be associated with concern about the disclosure of personal data, these activities require, above all, a higher level of knowledge (e.g., video preparation and editing, image graphic processing, etc.). We also detected three groups of activities: increasing (data storage, internet banking, travel information searching, product and service information search, videotelephony), stable (publishing of photos, reading news/magazines/newspapers, social media) and stagnating (online sale). In all activities, with the exception of online sales, an increase in the proportion of citizens who use individual activity can be observed over the years. 
Figure 4: Share of citizens who use individual services on the Internet

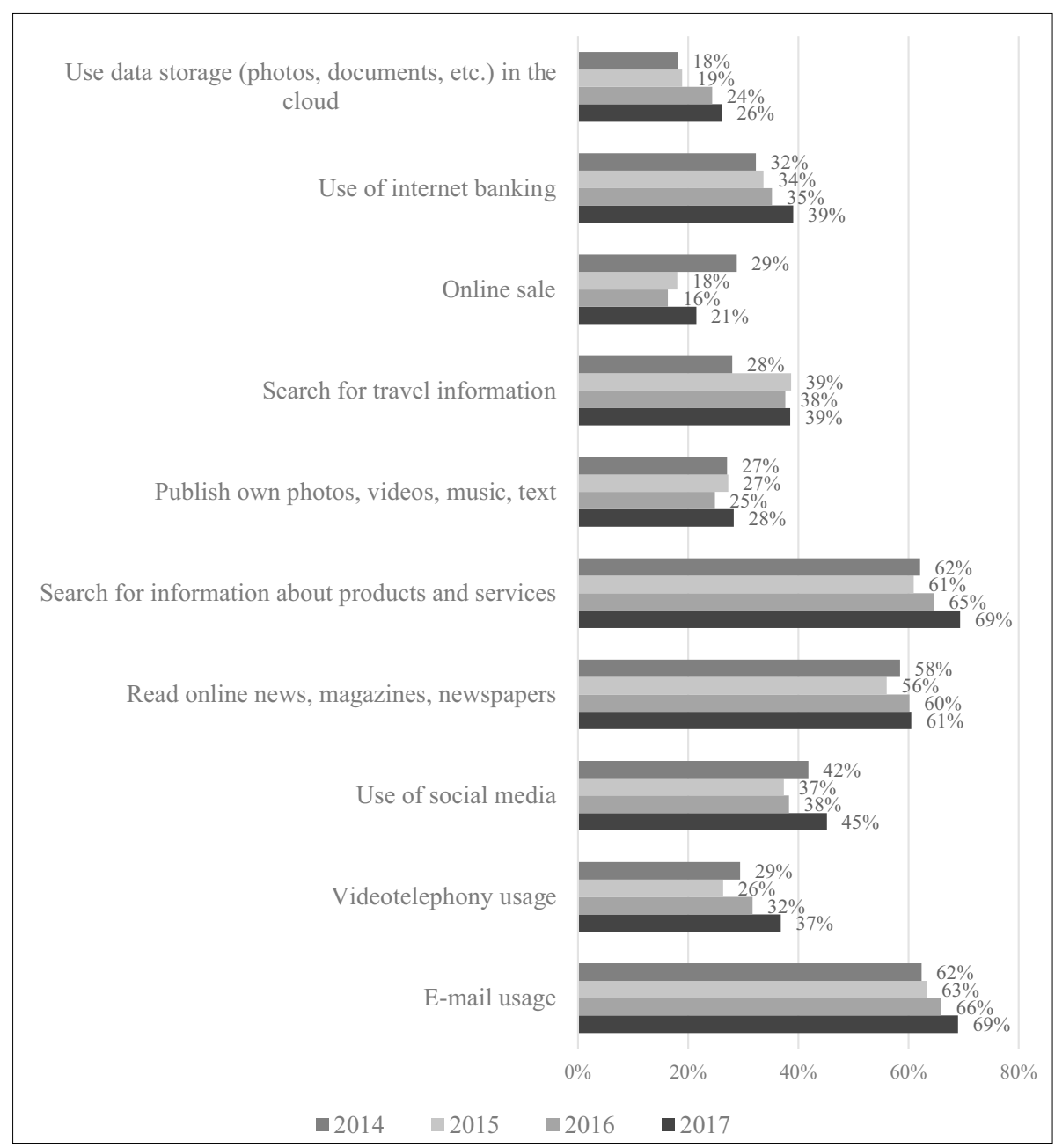

Source: own.

The government can also offer a lot of benefits to citizens by providing online content and services on the Internet. On the one hand, such offer brings advantages and benefits for users, and on the other hand also for the government. For more than a decade, Slovenia has more or less successfully been developing and offering various government websites and portals, most often in accordance with its strategies and action plans. Nevertheless, the results are alarming. Although an increasing number of citizens use the Internet and carry out various activities in this respect, the level of use within the public sector is decreasing and remains at a low level (Figure 5). The differences between the years are statistically significant, which was confirmed by the chisquare test $(p<.05)$. 
Figure 5: Share of citizens who are regular Internet users and use individual public administration services

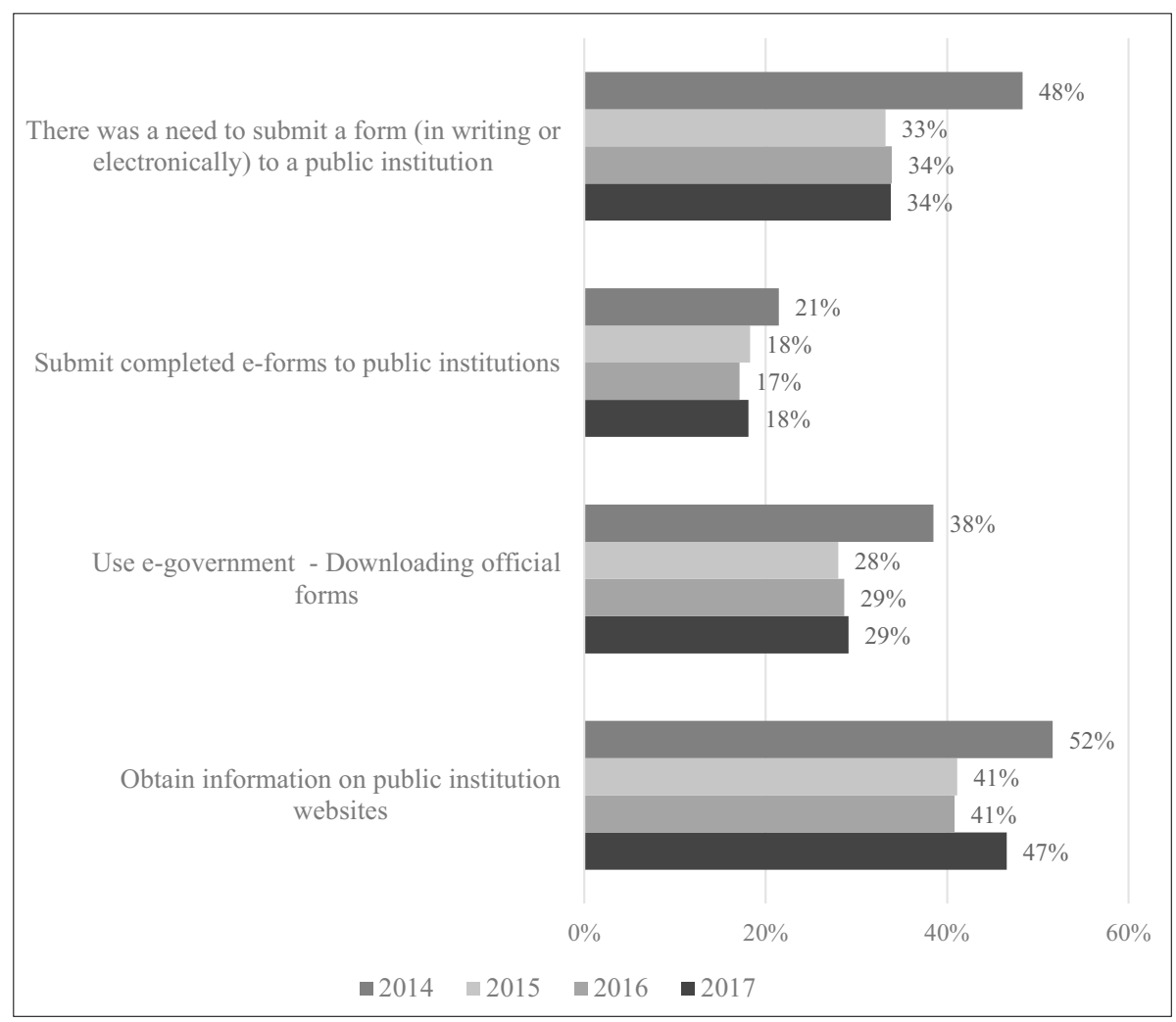

Source: own.

In particular, the transactional level of services, such as e-form submission over the Internet, is quite low. Data analysis summary shows that only about half of the people who had the need to submit any kind of form in the past months have submitted it electronically. The main reasons for this behaviour (Figure 6) were the lack of knowledge and concern about the safety and protection of personal data. From the fact that the proportion of those who have failed to submit the form because it was not available increases and the proportion of those who have failed to submit the form due to of the lack of knowledge decreases, we can conclude that the knowledge of the users is improving and that people increasingly look for online services and already perceive a lack of what they need, in this case electronic submission of forms. 
Figure 6: The share of citizens who had to submit a form to a public institution physically or electronically but failed to do so electronically. The year 2014 is not indicated due to inaccurate data that was the result of incorrect interpretation of questions by the participants

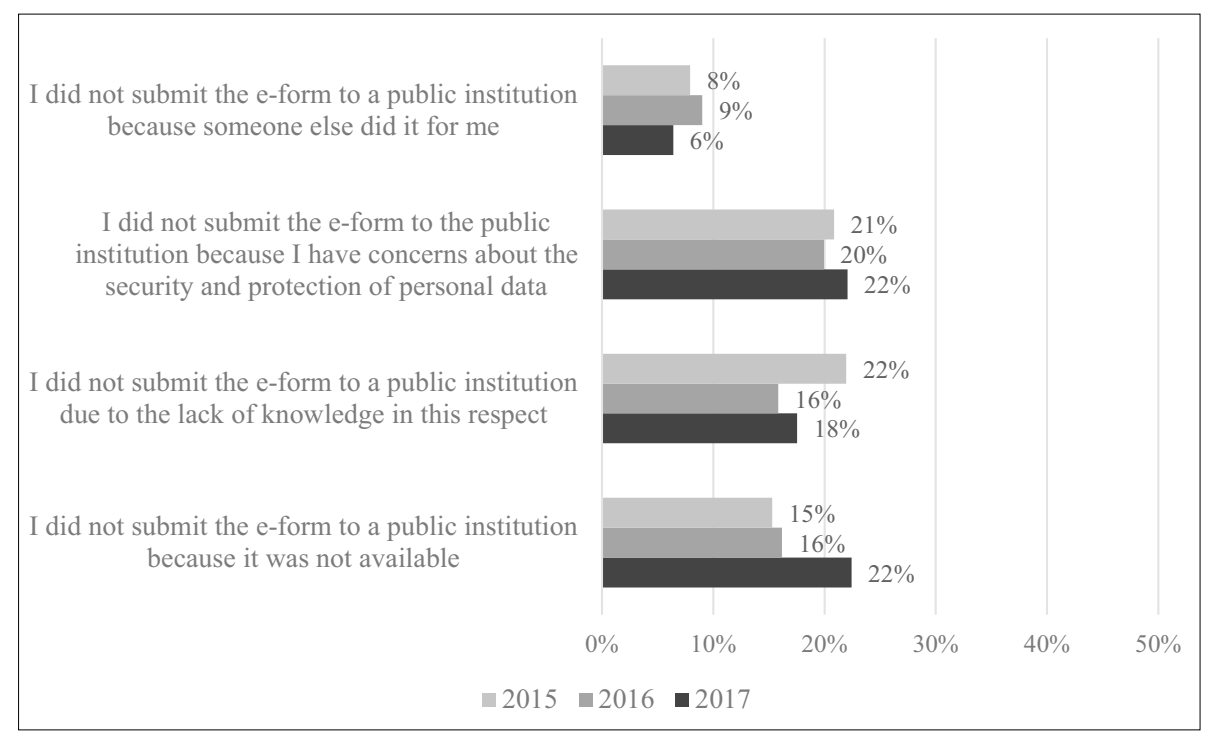

Source: own.

The results show that based on the monthly income of the respondents, there are statistically significant differences between the income groups in terms of certain categories (Table 1). Similar results are shown by other researchers.

The results also show that, according to the education of the respondent, there are statistically significant differences between the education groups in terms of some categories (Table 2). Regarding the services of obtaining information and forms, in all four years the first two categories (basic education or less and short or secondary vocational education) significantly differ from general or technical secondary education group, and the latter from the highest group. In some years, there is twice the difference between the lowest and the highest group. Regarding the most demanding services (submission of completed e-forms to public institutions), we can notice a triple difference between the first and the last group, which indicates that knowledge is of key importance for this type of services. Similar impacts of education on digital inequality were also determined by other authors (Sharma, 2015; Weiss, Yates, and Gulati, 2016). 


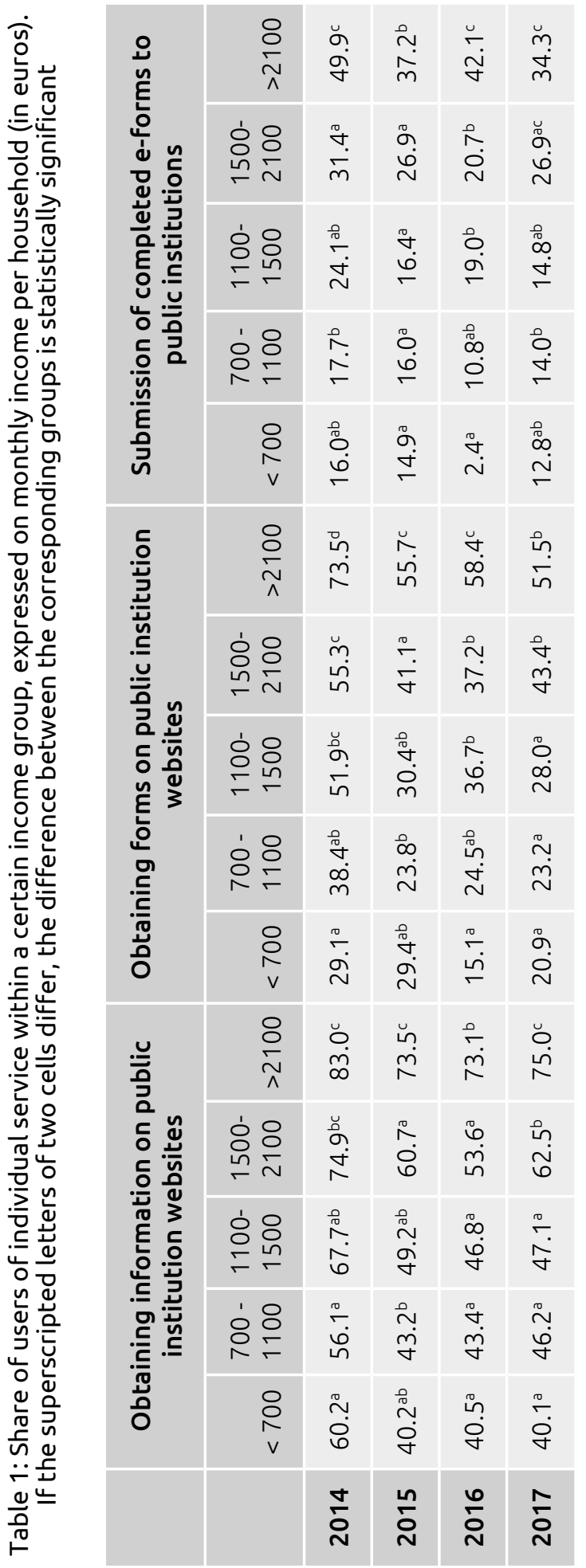

Central European Public Administration Review, Vol. 16, No. 2/2018 207 


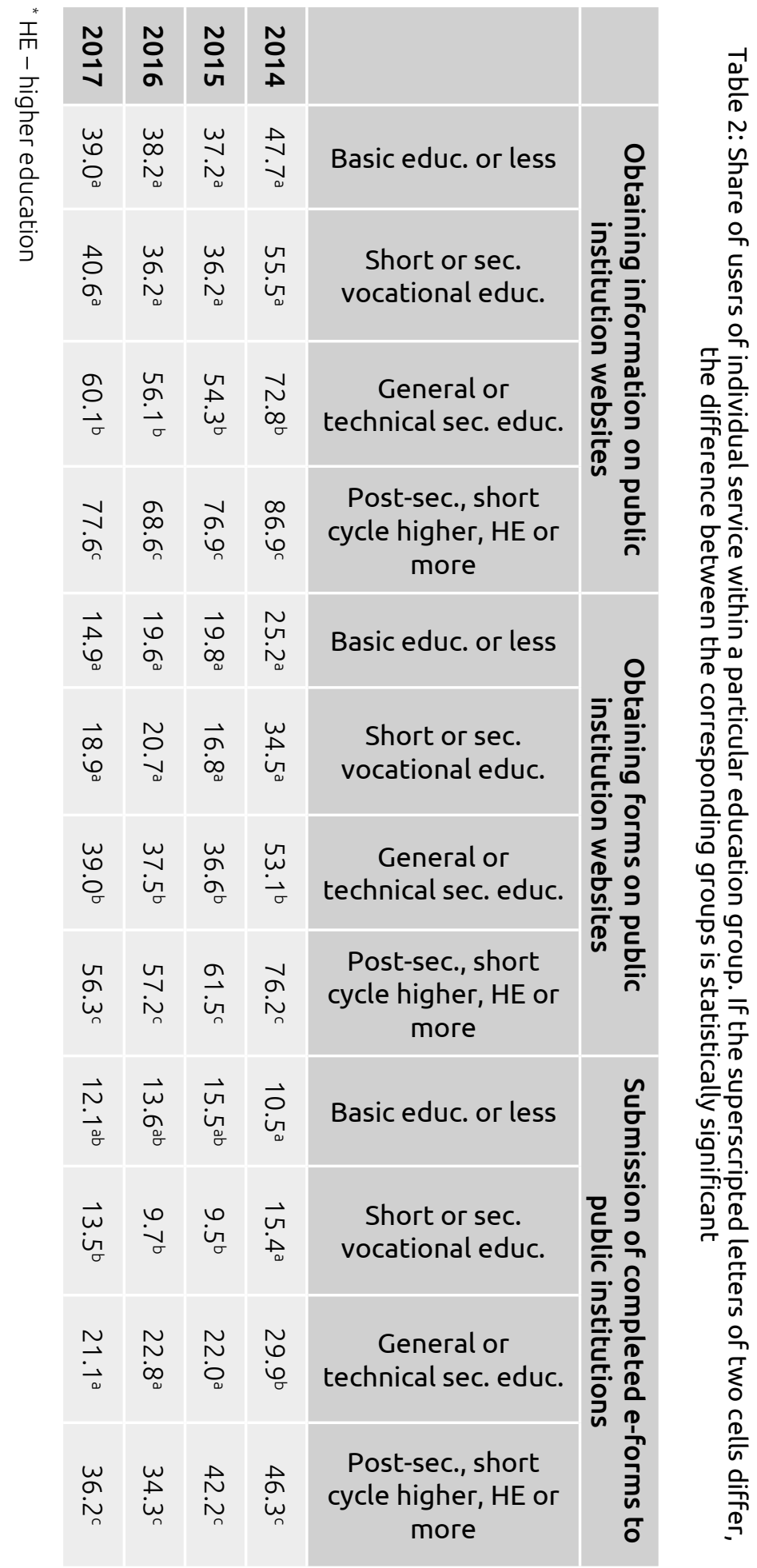




\section{Discussion}

The results show that Slovenian society, like the rest of the EU, is developing quite successfully in the field of ICT. Despite the less favourable results or the lagging behind the best in the $\mathrm{EU}$, we can observe an increase in most indicators of individuals and households with Internet access. The biggest jump is observed in the mobile phone Internet access indicator (34\% of users in 2014, $70 \%$ of users in 2017). This increase might be largely due to increased offer of mobile data transmission by various domestic and foreign providers and in lower prices. Increased competition on the part of providers, the entry of some new foreign providers into the Slovenian market, and the popularisation of the use of smartphones and applications have certainly contributed to improvements. A major step, indirectly linked to these indicators, is certainly also a change in roaming charges in the EU and the so called Roaming Like at Home initiative (European Commission, 2015; European Commission, 2016), which convinced many to start using mobile Internet abroad; however, there is still a low level of broadband Internet access in households, which can be slightly compensated with rapid mobile data transmission (4G); nevertheless, Slovenia still needs to carry out considerable work in this field in the coming years. The steps are defined in the Next-Generation Broadband Network Development Plan to 2020 (Ministry of Education, Science and Sport, 2016b), under which Slovenia, as a member of the EU, is to pursue the goal of the Digital Agenda for Europe, that is to enable all citizens access to broadband connections above $30 \mathrm{Mb} / \mathrm{s}$, and ensure that at least half of households are subscribe to internet connections above $100 \mathrm{Mb} / \mathrm{s}$ by 2020. Research has showed that the higher the broadband speed the higher the chance of an increased household income (Rohman and Bohlin, 2013).

According to data from 2017, around 130,000 Slovenian households still do not have an Internet connection. The reason, aligned with the research results of others (van Dijk and Hacker, 2003; Chetty et al., 2017), given by most of them is that they do not need the Internet (almost all the respondents have no children). Among these are more than 100,000 households with respondents over the age of 55, the group that distinguishes Slovenia most from the developed European countries in terms of internet users (European Commission, 2018). To decrease the influence of age within the digital inequality, the government should put more effort into simplifying e-services and training elderly people, especially at the level of safe use, which will also increase trust in the Internet and e-services (Alzahrani, Al-Karaghouli, and Weerakkody, 2017).

The knowledge of those who have used the Internet in the last 12 months is worse than the European average. It is a cause for concern because in the last four years the situation in this area has not changed much and also the level of users' computer programming knowledge, especially young people, has not increased. Given the needs of the market and the trend towards new, digitally oriented jobs, Slovenia should consider appropriate upgrades of the 
school curriculum in the context of formal education and encourage young people to develop digital skills and knowledge since this knowledge is becoming critical for generating new knowledge (Fluck et al., 2016). At the same time, schools should consider differences in socioeconomic status of students since it effects their digital skills capability (Aesaert and van Braak, 2015). Furthermore, researchers have found that better digital skills of adolescents enable better online opportunities and decrease online risk (Rodríguez-de-Dios, van Oosten, and Igartua, 2018).

Although changes are taking place in connection with the increasing presence and number of services of public institutions on the Internet over the years, the level of use is not increasing. The renovated government portal eUprava, new services on the Slovenian business point portal and eTax portal, the COBISS library system with its mobile application, the eHealth portal and mandatory e-invoices for operations with public sector are just some of the novelties of the past years; however there seems to be no breakthrough. On the one hand, the reason behind it could be in the complexity of the use of technology, especially the digital certificates, which presents many problems to technically less capable citizens. On the other hand, only less than half of the Internet users browse the websites of public institutions. Although researchers found that in more developed countries the use of complex government services online is not corelated to the digital skills level (Ebbers, Jansen, and van Deursen, 2016) we evaluate that situation in Slovenia is different. The first opportunity to change the situation we are faced with is an opportunity in connection with new trust services, such as smsPASS, which enable citizens to simply identify and use services through smartphones without any specific software or digital skills and with the use of mobile technology. But the government will have to increase its investment in promotional activities, stressed as crucial awareness and adoption factor (Yang, 2016), as citizens are poorly familiar or not familiar with different possible uses of the Internet regarding the provision of services or simply the availability of information. At the same time, public sector service providers, in cooperation with experts in this field and especially with end users, will need to put a lot of effort into the analysis of the user experience. Only then will users be eager to use online services and even increase the existing use, as explored by Kumar, Sachan, and Mukherjee (2017).

Furthermore, the results of our research show a significant influence of the level of education and income group on all three measured indicators of public institution service use. Similarly, the analysis of 146 countries by Weiss, Yates, and Gulati (2016) showed that higher levels of income and education enhance broadband affordability. According to our analysis by income groups, the top income group (more than EUR 2,100 monthly income per household), with statistically significant better results than other groups, clearly stands out. In 2017, this distinctive difference was lost in comparison with a slightly lower income group (between EUR 1,500 and EUR 2,100 monthly income per 
household), which is a positive indicator of change. However, the first three lower income groups show a lower level of use (the same significance class), which proves that the financial level of the household affects the level of use of the public-sector web services, and that EUR 1,500 monthly income per household is the line between one and the other. If the public sector wants to encourage citizens to use developed, established websites and services, it will have to look for ways to enable them to those with lower income.

The analysis of the differences between classes shows that online services of public institutions are mainly used by well-educated people. In some cases, the difference between the lowest (basic education or less) and the highest classes (post-secondary, short cycle higher, higher education or more) is more than double (e.g. obtaining information on the websites of public institutions). The difference has been decreasing over the years, but by a maximum of 10 percentage points. However, for technically more demanding services, which also require more knowledge (submission of completed e-forms to public institutions), the statistically significant differences between the lowest and the highest classes are even greater (from 20 to 35 percentage points). Other EU member states, even the most developed (Cruz-Jesus et al., 2016) face similar differences. Government's activity aimed at increasing the use of online services by public institutions is seen in promoting the offer and simplifying services, especially those that are more demanding. Above all, the offer must ensure the usability and efficiency of e-services (Chipeva et al., 2018). Based on the analysis, we can refute our first hypothesis that Slovenia has progressed regarding the level of the use of public sector e-services in the period under consideration. Despite the fact that in 2014 the results were high, which suggests the influence of a slightly different methodology, the indicators of other years indicate stagnation and virtually no visible progress in this area. Therefore, based on the analysis we can refute our second hypothesis. The results show that according to the monthly income of the respondent, there are statistically significant differences for certain categories between the income groups, which means that the differences do not decrease from the point of view of digital inequality. The statistically significant differences between income and education classes remain and are detected by other researchers as well (Aesaert and van Braak, 2015).

\section{Limitations}

This research used an established survey Use of Information and Communication Technology in Households and by Individuals, defined by EUROSTAT. For a more thorough future research we suggest that the questionnaire should be upgraded to a level where the dichotomous variables would be replaced by ordinal ones, thus enabling better statistical testing but at the same time preserve backward compatibility with previous surveys. 
Additionally, the survey data used in our research is based on the answers and opinions of the respondents and is therefore subjective. Especially with the questions of self-evaluation (like digital skills) some research shows that people tend to evaluate their knowledge better than it actually is.

Using the univariate analysis of the impact of digital inequality factors on the use of e-government services we could not asses the relative impact of individual factors.

We also detected a higher deviation of the results from the year 2014. We acknowledged this in our analysis but would suggest skipping that year in the future research.

\section{Conclusion}

In information society the use of information technology by citizens depends on the availability, reliability, security, and efficiency of the services offered (Sharma, 2015). In terms of information society and e-government development indicators, Slovenia is within the European average, which is a poor result for a country that started with the development of information society and e-business in public administration two decades ago. At the level of the use of online services by public institutions, the results could be better, as the computerised databases and registers in Slovenia enable the development of services that follow the main principles of e-government development, such as the provision of distance services, one-stop-shop concept and once-onlyprinciple including the compulsory electronic exchange of data between the organisations of public administration.

To evaluate the development of the filed in the last years the analysis was carried out on a representative sample of Slovenian citizens and reflects the situation in the entire Slovenian society. The results show a lack of progress in many areas and warn about the present economic and education divide of the society. To overcome the obstacles and improve the situation Slovenian government must transform the already established and well written strategies in concrete actions with a focus on deprived groups. The only thing that counts is what ultimately reflects in society and leads it to a better future, for which concrete steps are needed.

Future research could focus on comparison of all EU countries which are similar to Slovenia, especially those that made a better progress in the field under consideration. Such results could increase the identification of best possible actions for better development of information society and its e-government. Using the accessible data from EURSOTAT we also suggest the use of multivariate analysis as a venue for future research. 


\section{References}

Aesaert, K., and van Braak, J. (2015). Gender and socioeconomic related differences in performance based ICT competences. Computers \& Education, 84, pp. $8-25$.

Agresti, A. (2007). An introduction to categorical data analysis, $2^{\text {nd }}$ ed. Hoboken, $\mathrm{NJ}$ : Wiley.

Alzahrani, L., Al-Karaghouli, W. and Weerakkody, V. (2017). Analysing the critical factors influencing trust in e-government adoption from citizens' perspective: A systematic review and a conceptual framework. International Business Review, 26(1), pp. 164-175.

Carter, L., Schaupp, L. C., Hobbs, J. and Campbell, R. (2012). E-Government Utilisation: Understanding the Impact of Reputation and Risk. International Journal of Electronic Government Research, 8(1), pp. 83-97.

Castells, M. (2011). The Rise of the Network Society - The Information Age: Economy, Society and Culture. Ney York: John Wiley and Sons.

Chetty, K., Qigui, L., Gcora, N., Josie, J., Wenwei, L. and Fang, C. (2017). Bridging the digital divide: measuring digital literacy. Economics Discussion Papers, 69.

Chipeva, P., Cruz-Jesus, F., Oliveira, T. and Irani, Z. (2018). Digital divide at individual level: Evidence for Eastern and Western European countries. Government Information Quarterly, 35(3), pp. 460-479.

Cruz-Jesus, F., Vicente, M. R., Bacao, F. and Oliveira, T. (2016). The education-related digital divide: An analysis for the EU-28. Computers in Human Behavior, 56, pp. 72-82.

Davies, R. (2015). eGovermnent: Using technology to improve public services and democratic participation, EPRS, European Parliamentary Research Service Members' Research Service, September, PE 565.890.

DiMaggio, P., Hargittai, E., Celeste, C. and Shafer, S. (2004). From unequal access to differentiated use: A literature review and agenda for research on digital inequality. Social Inequality (23), pp. 355-400.

Ebbers, W. E., Jansen, M. G. M., and van Deursen, A. J. A. M. (2016). Impact of the digital divide on e-government: Expanding from channel choice to channel usage. Government Information Quarterly, 33(4), pp. 685-692.

European Commission. (2005). eEurope 2005: Benchmarking indicators, COM (2002) 655. At <http://europa.eu.int/information_society/eeurope/news_lib rary/documents/benchmarking05_en.pdf>, accessed 8 June 2018.

European Commission. (2010a). A Digital Agenda for Europe. COM(2010)245. At <https://eur-lex.europa.eu/LexUriServ/LexUriServ.do?uri=COM:2010:0245: FIN:EN:PDF>, accessed 12 June 2018.

European Commission. (2010b). EUROPE 2020, A European strategy for smart, sustainable and inclusive growth. COM(2010)2020. At <https://eur-lex.europa.eu/LexUriServ/LexUriServ.do?uri=COM:2010:2020:FIN:EN:PDF>, accessed 12 June 2018.

European Commission. (2015). REGULATION (EU) 2015/2120 OF THE EUROPEAN PARLIAMENT AND OF THE COUNCIL of 25 November 2015 laying down measures concerning open internet access and amending Directive 2002/22/EC on universal service and users' rights relating to electronic communications networks and services and Regulation (EU) No 531/2012 on roaming on public mobile communications networks within the Union. At <https://eur-lex. europa.eu/legal-content/EN/TXT/HTML/?uri=CELEX:32015R2120andfrom $=\mathrm{S}>$, accessed 18 May 2018. 
European Commission. (2016). COMMISSION IMPLEMENTING REGULATION (EU) 2016/2286 of 15 December 2016 laying down detailed rules on the application of fair use policy and on the methodology for assessing the sustainability of the abolition of retail roaming surcharges and on the application to be submitted by a roaming provider for the purposes of that assessment. At <https://eur-lex.europa.eu/legal-content/EN/TXT/HTML/?uri=CELEX:32016R2 286andfrom=SL>, accessed 18 August 2018.

European Commission. (2018). Digital Economy and Society Index (DESI) 2018, Methodological note. At< http://ec.europa.eu/information_society/ newsroom/image/document/2018-20/si-desi_2018-country-profile_eng_ B4415E5E-051F-2B7A-95E133B50A52479E_52237.pdf>, accessed $\overline{3}$ July 2018.

Fluck, A., Webb, M., Cox, M., Angeli, C., Malyn-Smith, J., Voogt, J. and Zagami, J. (2016). Arguing for Computer Science in the School Curriculum. Journal of Educational Technology and Society, 19(3), pp. 38-46.

Garson, G. D. (2006). Public Information Technology and E-governance: Managing the Virtual State. Sadbury, MA: Jones and Bartlett Learning.

Gascó-Hernández, M. (2014). Open Government: Opportunities and Challenges for Public Governance. New York: Springer Science and Business Media.

Government of the Republic of Slovenia. (2016). The Slovenian National Cyber Security Strategy. At <http://www.uvtp.gov.si/fileadmin/uvtp.gov.si/pageup loads/Cyber_Security_Strategy_Slovenia.pdf>, accessed 6 june 2018.

Hughes, E., Graham, L., Rowley, L. and Lowe, R. (2018). Unlocking Blockchain: Embracing New Technologies to drive Efficiency and Empower the Citizen. The JBBA (1), 3741.

Hüsing, T., Korte, W. B. and Dashja, E. (2015). e-Skills in Europe, Trends and Forecasts for the European ICT Professional and Digital Leadership Labour Markets (2015-2020), empirica Working Paper. At <http://eskills-lead.eu/fileadmin/lead/brochure-lead/working_paper_-_supply_demand_forecast_2015_a. $p d f>$, accessed 8 June 2018.

Kumar, R., Sachan, A., and Mukherjee, A. (2017). Qualitative approach to determine user experience of e-government services. Computers in Human Behavior, 71, pp. 299-306.

Michaels, G., Natraj, A. and Van Reenen, J. (2014). Has ICT polarised skill demand? Evidence from eleven countries over twenty-five years. Review of Economics and Statistics, 96(1), pp. 60-77.

Ministry of Education, Science and Sport. (2016a). Digital Slovenia 2020 - Development strategy for the information society until 2020. At <http://www. mju.gov.si/fileadmin/mju.gov.si/pageuploads/DID/Informacijska_druzba/pdf/ DSI_2020_3-2016_pic1.pdf>, accessed 4 July 2018.

Ministry of Education, Science and Sport. (2016b). The Next Generation Broadband Network Development Plan to 2020. At <http://www.mju.gov.si/ fileadmin/mju.gov.si/pageuploads/DID/Informacijska_druzba/NGN_2020/ NGN_2020_Slovenia_EN.pdf>, accessed 12 July 2018.

Ministry of Public Administration. (2015). Public administration 2020, Public administration development strategy 2015-2020. At <http://www.mju.gov.si/ fileadmin/mju.gov.si/pageuploads/JAVNA_UPRAVA/Kakovost/Strategija_raz voja_ANG_final_web.pdf>, accessed 8 September 2018.

Misuraca, G., Codagnone, C. and Rossel, P. (2013). From Practice to Theory and back to Practice: Reflexivity in Measurement and Evaluation for Evidence-based Policy Making in the Information Society. Government Information Quarterly, 30, pp. 68-82. 
Nath, H. K. (2017). The Information Society, SSRN Scholarly Paper. Rochester, NY: Social Science Research Network. At <https://papers.ssrn.com/abstract=3077759>, accessed 15 June 2018.

OECD. (2001). Understanding the Digital Divide. At <https://www.oecd-ilibrary. org/science-and-technology/understanding-the-digital-divide_2364056677 66>, accessed 23 May 2018.

OECD. (2018). Bridging the Digital Divide. At <http://www.oecd.org/going-digital /bridging-the-digital-gender-divide-key-messages.pdf>, accessed 23 September 2018.

Palvia, S. C. J. and Sharma, S. S. (2007). E-government and e-governance: definitions/domain framework and status around the world. International Conference on E-governance, pp. 1-12.

Rodríguez-de-Dios, I., van Oosten, J. M., and Igartua, J.-J. (2018). A study of the relationship between parental mediation and adolescents' digital skills, online risks and online opportunities. Computers in Human Behavior, 82, pp. 186-198.

Rohman, I. K., and Bohlin, E. (2013). The impact of broadband speed on the household income: comparing OECD and BRICs. 24 ${ }^{\text {th }}$ European Regional Conference of the International Telecommunications Society, Florence, Italy.

Sharma, S. K. (2015). Adoption of e-government services: The role of service quality dimensions and demographic variables. Transforming Government: People, Process and Policy, 9(2), pp. 207-222.

Statistical Office of the Republic of Slovenia. (2018). Use of ICT in Households. At <https://www.stat.si/StatWeb/en/Field/Index/10/2989>, accessed 23 September 2018.

Tilly, C. (1998). Durable inequality. Berkeley: University of California Press.

van Dijk, J. and Hacker, K. (2003). The digital divide as a complex and dynamic phenomenon. The Information Society, 19(4), pp. 315-326.

Wang, Y.-S. and Liao, Y.-W. (2008). Assessing eGovernment systems success: A validation of the DeLone and McLean model of information systems success. Government Information Quarterly, 25(4), pp. 717-733.

Webster, F. (2014). Theories of the Information Society. New York, ZDA: Routledge.

Weerakkody, V., El-Haddadeh, R., Sabol, T., Ghoneim, A. and Dzupka, P. (2012). E-government implementation strategies in developed and transition economies: A comparative study. International Journal of Information Management, 32(1), pp. 66-74.

Weiss, J. W., Yates, D. J. and Gulati, G. J. J. (2016). Affordable Broadband: Bridging the Global Digital Divide, a Social Justice Approach. In 49th Hawaii International Conference on System Sciences (HICSS), pp. 3848-3857.

Yang, Y. (2016). What Determines a Successful e-Government Promotion? In European Conference on e-Government (p. 317). Academic Conferences International Limited.

Yuan, L., Xi, C. and Xiaoyi, W. (2012). Evaluating the readiness of government portal websites in China to adopt contemporary public administration principles. Government Information Quarterly, 29(3), pp. 403-412. 